\title{
REVIEW
}

\section{Clinical review: Continuous and simplified electroencephalography to monitor brain recovery after cardiac arrest}

\author{
Hans Friberg ${ }^{* 1,2}$, Erik Westhall2,3, Ingmar Rosén ${ }^{2,3}$, Malin Rundgren ${ }^{1,2}$, Niklas Nielsen²,4 and Tobias Cronberg ${ }^{2,5}$
}

\begin{abstract}
There has been a dramatic change in hospital care of cardiac arrest survivors in recent years, including the use of target temperature management (hypothermia). Clinical signs of recovery or deterioration, which previously could be observed, are now concealed by sedation, analgesia, and muscle paralysis. Seizures are common after cardiac arrest, but few centers can offer high-quality electroencephalography (EEG) monitoring around the clock. This is due primarily to its complexity and lack of resources but also to uncertainty regarding the clinical value of monitoring EEG and of treating post-ischemic electrographic seizures. Thanks to technical advances in recent years, EEG monitoring has become more available. Large amounts of EEG data can be linked within a hospital or between neighboring hospitals for expert opinion. Continuous EEG (cEEG) monitoring provides dynamic information and can be used to assess the evolution of EEG patterns and to detect seizures. CEEG can be made more simple by reducing the number of electrodes and by adding trend analysis to the original EEG curves. In our version of simplified cEEG, we combine a reduced montage, displaying two channels of the original EEG, with amplitude-integrated EEG trend curves (aEEG). This is a convenient method to monitor cerebral function in comatose patients after cardiac arrest but has yet to be validated against the gold standard, a multichannel cEEG. We recently proposed a simplified system for interpreting EEG rhythms after cardiac arrest, defining four major EEG patterns. In this topical review, we will discuss cEEG to monitor brain function after cardiac arrest in general and how a simplified $c E E G$, with a reduced number of electrodes and trend analysis, may facilitate and improve care.
\end{abstract}

\section{Introduction}

Patients who qualify for intensive care are generally severely ill with failure of vital organs. The major threat for comatose cardiac arrest patients with stabilized cardiac function is imminent brain injury, which accounts for approximately two thirds of the mortality $[1,2]$.

The clinical picture of neurologic recovery has been altered in recent years because of more active care of cardiac arrest survivors, including the use of induced hypothermia [3,4]. Clinical signs of recovery or deterioration are now concealed by sedation, analgesia, and muscle paralysis. Clinically overt seizures as well as nonconvulsive electrographic seizures, including electrographic status epilepticus (ESE), are common features

${ }^{*}$ Correspondence: hans.friberg@skane.se

'Department of Intensive and Perioperative Care, Skåne University Hospital,

Getingevägen, 22185 Lund, Sweden

Full list of author information is available at the end of the article after cardiac arrest [5-10] and may be provoked by rewarming and weaning of sedative drugs. Continuous electroencephalography (cEEG) is a non-invasive technique that may be used to monitor the post-ischemic brain after cardiac arrest but is not yet common practice in most intensive care units (ICUs). In fact, few centers outside the major hospitals have the ability to perform high-quality EEG monitoring around the clock, probably because of its complexity and a lack of resources [11].

Thanks to recent technical advances, EEG monitoring has become more available, allowing large amounts of EEG data to be linked within a hospital or between neighboring hospitals for support and expert opinion. cEEG provides dynamic information and can be used to monitor the evolution of EEG patterns and to detect seizures, and this has prognostic implications. For cEEG to reach general use, it should be simple, cost-effective, and possible to apply bedside. A step in that direction is to reduce the number of electrodes and to add trend analysis to the original EEG curves [11]. In our version of simplified cEEG, we combine a reduced montage, 
displaying two channels of the original EEG, with amplitude-integrated EEG (aEEG) trend curves [10,12,13]. This is a convenient method to monitor cerebral function in comatose patients after cardiac arrest but has yet to be validated against the gold standard, a multichannel cEEG [11]. In this topical review, we will discuss cEEG for monitoring of brain function after cardiac arrest in general and how a simplified cEEG, with a reduced number of electrodes and trend analysis, may facilitate and improve care in the ICU.

\section{Evaluation of prognosis after cardiac arrest}

The best indicator of a good recovery after cardiac arrest is for a patient to awaken and make intentional movements spontaneously or as a response to painful stimulation soon after rewarming, when sedation and analgesia have been turned off [14]. Some patients recover later, and this may be due to a residual effect of sedative drugs, a more pronounced ischemic insult, or a combination thereof. For those patients who remain in coma 4 to 5 days after the arrest, the prognosis is generally poor, but a minority will still make a good recovery [15]. A significant number of patients develop electrographic epileptic activity with or without clinically overt seizures [7-9]. This may evolve into an ESE, which is a poor sign, although survivors with good neurologic outcome are increasingly reported [16-18].

As a consequence of modern post-cardiac arrest care and related difficulties in assessing neurologic function, we need to improve and standardize our diagnostic and prognostic procedures. Early prognostication is important in order to give appropriate information to relatives and as a foundation for decisions on emergency interventions. Reliable prognostication at a later stage ( $\geq 4$ to 5 days) is of paramount importance for decisions on level of care, including withdrawal of life-sustaining therapy in patients with presumed poor outcome (vegetative state or death).

Several authors have stressed the importance of a multimodal strategy, implying that several methods should be used in parallel in order to strengthen the clinicians' capability to accurately predict a poor as well as a good outcome [19-21]. Recommended methods, other than a clinical neurologic examination, include EEG [10,22,23], somatosensory evoked potentials (SSEPs) [24,25], biochemical markers in peripheral blood [26], and brain imaging [27].

\section{Electroencephalography}

EEG has been used for many years to diagnose seizure activity in comatose patients after cardiac arrest and as an aid in evaluating prognosis. Since EEG patterns are depressed by sedatives, EEG may be used to monitor the depth of sedation as well as the effect of sedatives on electrographic epileptic activity. It may, however, be difficult to differentiate whether a specific EEG pattern is the result of sedation or of an underlying pathologic condition. Temperature also affects the EEG but is of less importance in the range down to $33^{\circ} \mathrm{C}$ [28]. Other limitations of EEG include its relative complexity; a conventional EEG is usually recorded from 20 scalp electrodes or more and requires expertise for interpretation of data. Also, the limited time allowed for a conventional EEG, usually 20 to 30 minutes, may not give the correct picture in a patient with intermittent seizure activity or varying levels of sedation.

Testing for EEG reactivity implies that the comatose patient is exposed to external stimuli (sound or pain) to assess whether the background EEG pattern reacts (amplitude or frequency content). Absence of EEG reactivity to stimuli during hypothermia treatment after cardiac arrest is shown to be strongly [29] but not invariably [30] associated with poor outcome.

\section{Continuous electroencephalography monitoring}

cEEG can be used to monitor evolution of EEG patterns, follow trends, and detect seizures over time. Traditionally, a multichannel montage, similar to that used in routine EEGs, has been used. In the neonatal ICU, cEEG has been used to monitor maturity of the brain in pre-term deliveries and to assess brain injury in the newborn, especially after asphyxia [31,32]. cEEG has also been used to assess brain injury in pediatric cardiac arrest patients treated with hypothermia, in whom it was found to be safe and feasible [33]. In the adult neuro-ICU, cEEG is increasingly used to evaluate conditions such as ESE [34], neurotrauma [35], and subarachnoidal hemorrhage [36], but its use in adult patients after cardiac arrest is still limited. The present use, limitations, and future directions of cEEG monitoring in the ICU were recently reviewed [11].

\section{Continuous electroencephalography with simplified montage}

To ease the introduction of cEEG in the ICU, a simplified montage with a reduced number of channels can be applied, but the limitations with this technique should be recognized. Sensitivity and specificity to detect (for example, seizures) are not the same as with a full-lead EEG [11]. In encephalopathic neonates, systematic studies of seizures indicate that approximately $80 \%$ of all seizures recorded with a conventional multichannel technique appear in the reduced montage [37]. Whether this rather high sensitivity to detect seizures holds true for adult encephalopathic patients after cardiac arrest is not known and needs to be addressed in future trials. Another example of a simplified cEEG montage is the commercially available four-channel subhairline montage, 
which recently was validated against conventional cEEG in patients at high risk of seizures [38]. cEEG can also be made more simple and accessible to the clinician by introducing computer-assisted EEG monitoring [39,40], which is an area of active research [41].

\section{Continuous electroencephalography with trend analysis}

When monitoring is performed over several days, quantitative EEG (qEEG) variables can be used to construct trend curves with compressed timescales [42]. The trend curve facilitates interpretation and helps identify certain events (for instance, seizures or changes in background pattern). There are many different qEEG variables to choose from, depending on what pathologic events you want to detect. For instance, spectral array analyses can be used to detect seizures, asymmetry index to detect ischemia due to vasospasm, and suppression ratio to monitor depth of sedation [42]. qEEG software is incorporated in most modern digital EEG monitors. In the present review, we will focus on trend analyses with aEEG, displayed in combination with a reduced number of original EEG channels to monitor brain function after cardiac arrest (Figure 1) [10,12]. Our experience is that cEEG with a simplified montage and aEEG trend analysis is well suited to follow transitions in background patterns and has acceptable sensitivity to detect clinically relevant electrographic seizures $[10,13]$. In a prospective study of 95 consecutive patients [10], ESE was diagnosed in 26 patients (27\%), which is comparable to findings in a retrospective study using conventional multichannel EEG recordings [9].

The relative simplicity of cEEG with a reduced montage and aEEG trend analysis makes it attractive and more accessible to generalists in the ICU. First, only two original EEG channels are displayed with standard filter settings (1 to $70 \mathrm{~Hz}$ ). Second, the EEG signal that builds up the aEEG is modified and filtered; signals with frequencies of clinical interest ( 2 to $15 \mathrm{~Hz}$ ) are amplified, and frequencies corresponding to artefacts, such as breathing $(<2 \mathrm{~Hz})$ or muscle activity $(>20$ to $25 \mathrm{~Hz})$, are reduced. Third, the amplitude scale is linear up to $10 \mu \mathrm{V}$ and semi-logarithmic thereafter, thereby facilitating interpretation of the lower amplitudes, which has clinical relevance. Fourth, the aEEG timeline is compressed to 4 or sometimes 6 hours per screen as compared with 10 seconds per screen in the original EEG. The upper edge of the aEEG, the aEEG maximum, correlates with periods of high amplitude in the EEG signal, whereas the lower border, the aEEG minimum, correlates with periods of low amplitude (Figure 1). In other words, the aEEG is an integrated and filtered signal of the maximum and minimum amplitudes of the original EEG.
We use subdermal needle electrodes according to the SI system in left frontal (F3), right frontal (F4), left parietal (P3), and right parietal (P4) positions with ground and reference electrodes in the midline (Figure 2). Impedance measurements are performed by the ICU nurse every 2 to 4 hours, and clinical events that are likely to produce artefacts are marked on the screen. Whenever in doubt about whether a change in the trend curve represents seizures or artefacts, the treating physician has immediate access to the corresponding original EEG in the lower panel by scrolling the bar to the specific time of interest (Figure 1). Suspected seizures in the simplified montage will lead, in many cases, to a routine EEG with video-recording in our institution in order to confirm or dismiss ongoing electrographic seizures.

cEEG montage with reduced number of electrodes has several advantages over the multichannel cEEG, above all its relative simplicity. Moreover, no expertise is needed to initiate monitoring of the patient, and the procedure can easily be integrated in general ICU care $[10,13]$. Therefore, we consider a simplified cEEG with aEEG trend analysis to be better adapted to a complex ICU environment than the more labor-intensive multichannel montage, which needs trained EEG technologists to start and maintain monitoring. As with conventional cEEG, patient data can easily be linked within a hospital or between hospitals in order for the attending physician to receive relevant support and help to interpret data from the neurophysiologists or neurologists. A close collaboration between intensivists, neurophysiologists, and neurologists is highly recommended and is probably a key to success. Also, all staff in the ICU should be offered basic education regarding potential sources of error and interpretation of $\mathrm{CEEG}$ in order to maximize its benefits $[43,44]$.

Epileptic activity following cardiac arrest tends to be generalized, but whether focal seizures are missed with a simplified montage needs to be addressed in a clinical trial, comparing a simplified montage with a full EEG montage. As with all EEG techniques, the simplified montage is relatively sensitive to movement and muscle artefacts, but as the monitoring spans over many hours, sections free of artefacts are almost always present. The prolonged monitoring may also facilitate interpretation of the EEG activity in relation to sedation. A disadvantage with a simplified montage is that it does not allow adequate evaluation of EEG reactivity to stimuli, which requires a multichannel conventional EEG. In our institution, we test for reactivity in a conventional EEG in all patients who remain in coma after recovery of normothermia and weaning of sedation.

Experience from simplified cEEG with aEEG trend monitoring originates above all from the neonatal environment, where the technique has become standard 


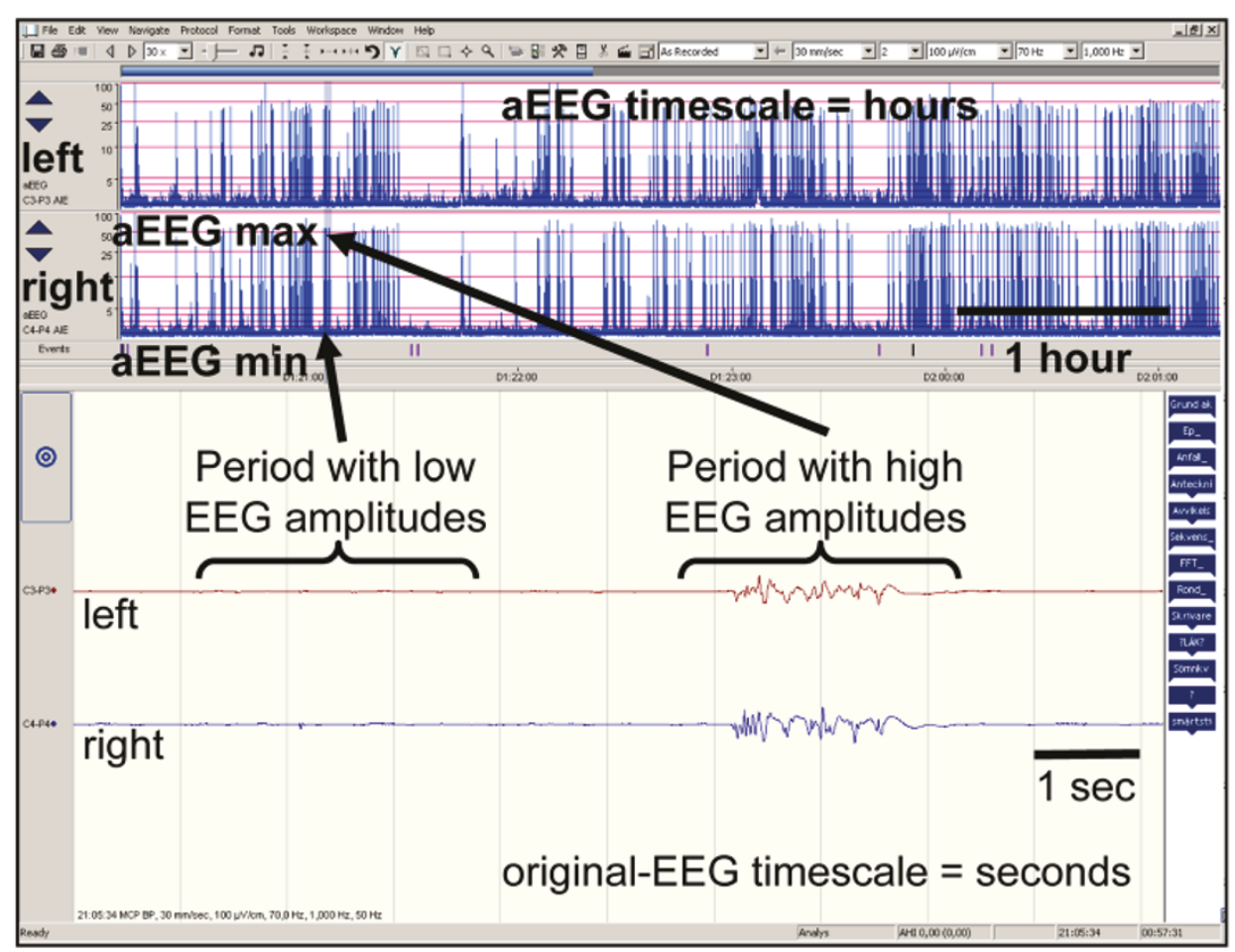

Figure 1. Trend monitor displays original electroencephalography (EEG) and amplitude-integrated EEG (aEEG) from two channels. The channels correspond to the left and right sides of the scalp. The aEEG timescale is compressed, showing 4 to 6 hours per screen. The aEEG trend is scanned by the interpreter for changes in background pattern or seizures, and details are explored in the corresponding original EEG. Clinical notes can be used to mark clinical events (for example, convulsions) to facilitate interpretation. In this display, a burst suppression pattern is shown. Suppression periods with low amplitudes in the original EEG correspond to the lower border of the aEEG trends (aEEG minimum level), and the burst periods correspond to the upper border (aEEG maximum level).

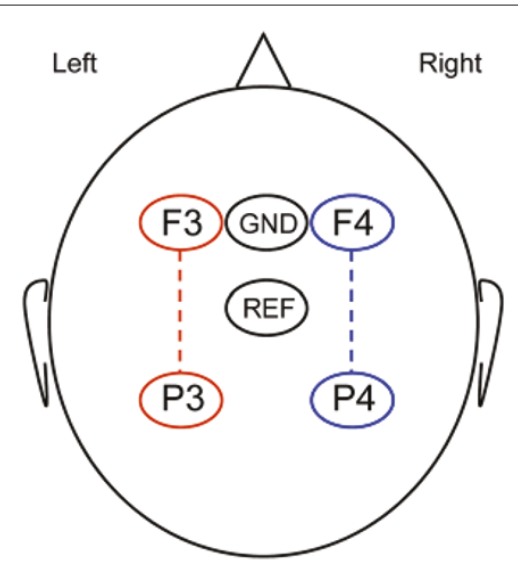

Figure 2. Example of a simplified electroencephalography montage. Four recording electrodes in left frontal (F3), right frontal (F4), left parietal (P3), and right parietal (P4) positions are shown with ground (GND) and reference (REF) electrodes in the midline. The original electroencephalography is displayed as two bipolar channels $($ F3-P3, F4-P4), one on each side (red = left, blue = right).

monitoring procedure for assessment of brain maturity and asphyxia in newborns. aEEG recordings within
6 hours after birth have been shown to correctly predict outcome after perinatal asphyxia in term infants [31]. Early normalization of aEEG and early onset of sleepwake cycling predict a good outcome [45]. Interestingly, hypothermia treatment changes the predictive value of early aEEG since normalization of an infant's aEEG pattern is delayed by hypothermia. Moreover, time to recover a normal aEEG is a better predictor than time to recover a sleep-wake cycling pattern in hypothermiatreated infants [46].

\section{Seizures, myoclonus, and electrographic status epilepticus after cardiac arrest}

An epileptic seizure is the manifestation of an abnormal and excessive synchronized discharge of cerebral neurons. Each seizure can be classified as a clinical seizure, which is what is observed, or an electrographic seizure, which is what is monitored with an EEG device. Clinical seizures are reported in approximately one fourth of all patients after cardiac arrest [7], but seizure mimics are common in the intensive care setting and may be difficult to differentiate from true epileptic seizures without the aid of EEG [47]. Correspondingly, electrographic seizures may or may not have clinical correlates [48]. 
(a)

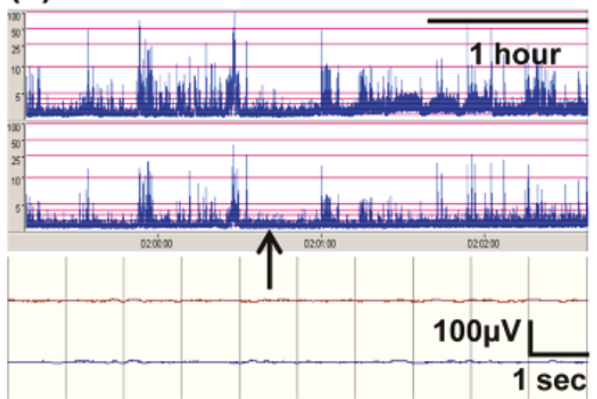

(c)

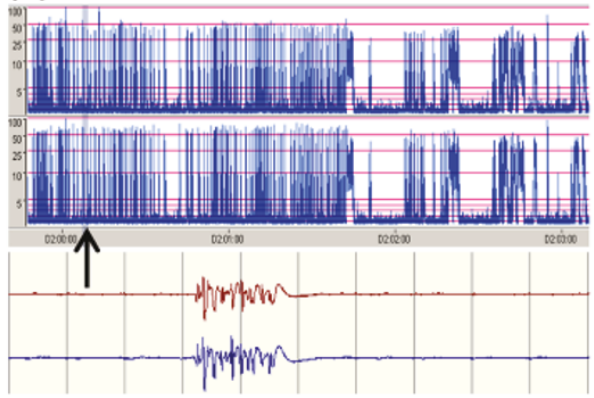

(b)

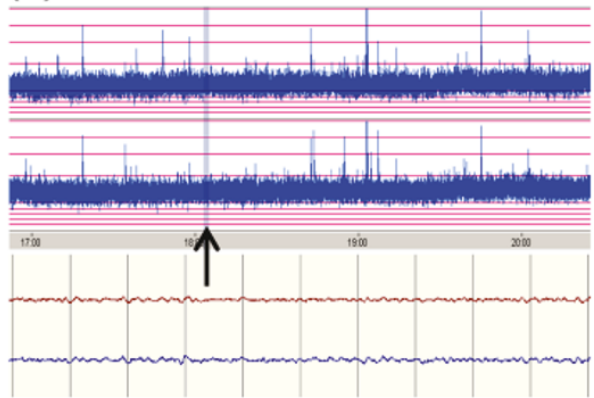

(d)

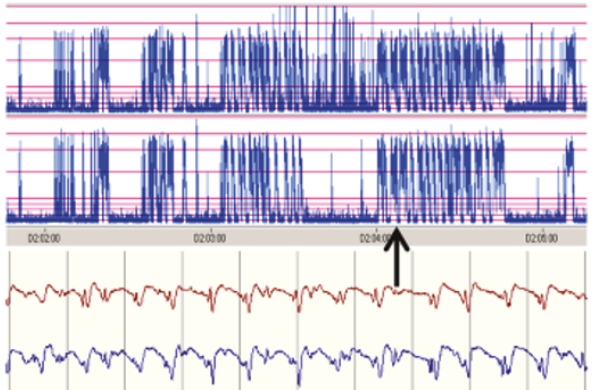

Figure 3. Four typical electroencephalography (EEG) patterns after cardiac arrest. (a) Flat. (b) Continuous background. (c) Burst suppression (BS). (d) Electrographic status epilepticus (ESE). The arrows in the amplitude-integrated EEG timescales represent the corresponding original EEG below.

Myoclonus is a common form of motor manifestation in the comatose survivor of cardiac arrest and consists of brief repetitive jerks, which may be irregular or rhythmic and spontaneous or stimulus-induced. It may occur in isolated muscles (focal) or be generalized in face, limbs, and axial musculature. Myoclonus may be of cortical or subcortical origin and occurs in approximately $20 \%$ of patients after cardiac arrest; myoclonus of cortical origin is the more common [30]. Prognosis is generally poor, especially when myoclonus occurs early after arrest of cardiac origin $(<24$ hours) and when it is generalized and persistent $[49,50]$. However, several case reports show that even an early and generalized myoclonus may be compatible with good neurologic recovery [51,52]. In a recent retrospective report from The Netherlands, $12 \%$ of all patients who had some kind of myoclonus eventually had a good outcome [30], but whether hypothermia treatment affects the incidence and prognosis of myoclonus is not clear. Lance-Adams syndrome denotes a chronic form of action-induced post-hypoxic myoclonus, which is more common after cardiac arrest of a primary hypoxic cause and compatible with a good outcome [53].

ESE occurs in a significant fraction of hypothermiatreated patients who remain unresponsive after rewarming [15] and is a predictor of a poor neurologic prognosis after cardiac arrest [9], although some patients may recover $[16,18]$. In a recent report, a subgroup of hypothermia-treated cardiac arrest patients with post-anoxic
ESE and a good outcome was described, and all had preserved brain stem reflexes and a reactive EEG [29]. This group of patients may be similar or identical to those who develop a late ESE from a cEEG pattern [10] and with a potentially good outcome.

A major question, yet to be answered, is whether postanoxic ESE is a condition that causes further brain injury, as indicated by a recent study [54], or is simply a sign of the hypoxic-ischemic encephalopathy. No systematic trials regarding treatment of post-anoxic ESE have been performed, and the available observational data do not allow conclusions about whether survival of patients is due to aggressive anti-epileptic treatment or merely to prolonged intensive care [55]. Nevertheless, most clinicians agree that visible seizures should be treated with anti-convulsive drugs, but there is no consensus on treatment strategy or duration.

\section{Evolution of electroencephalography patterns after cardiac arrest}

Our group recently proposed a simplified system for interpreting EEG rhythms in the post-ischemic brain after cardiac arrest in order to make EEG more comprehensible and more accessible at the bedside [10]. We defined four common EEG patterns after cardiac arrest, which are presented in Figure 3. Using these four patterns to classify the EEG generated valuable prognostic information, positive as well as negative [10]. In a 


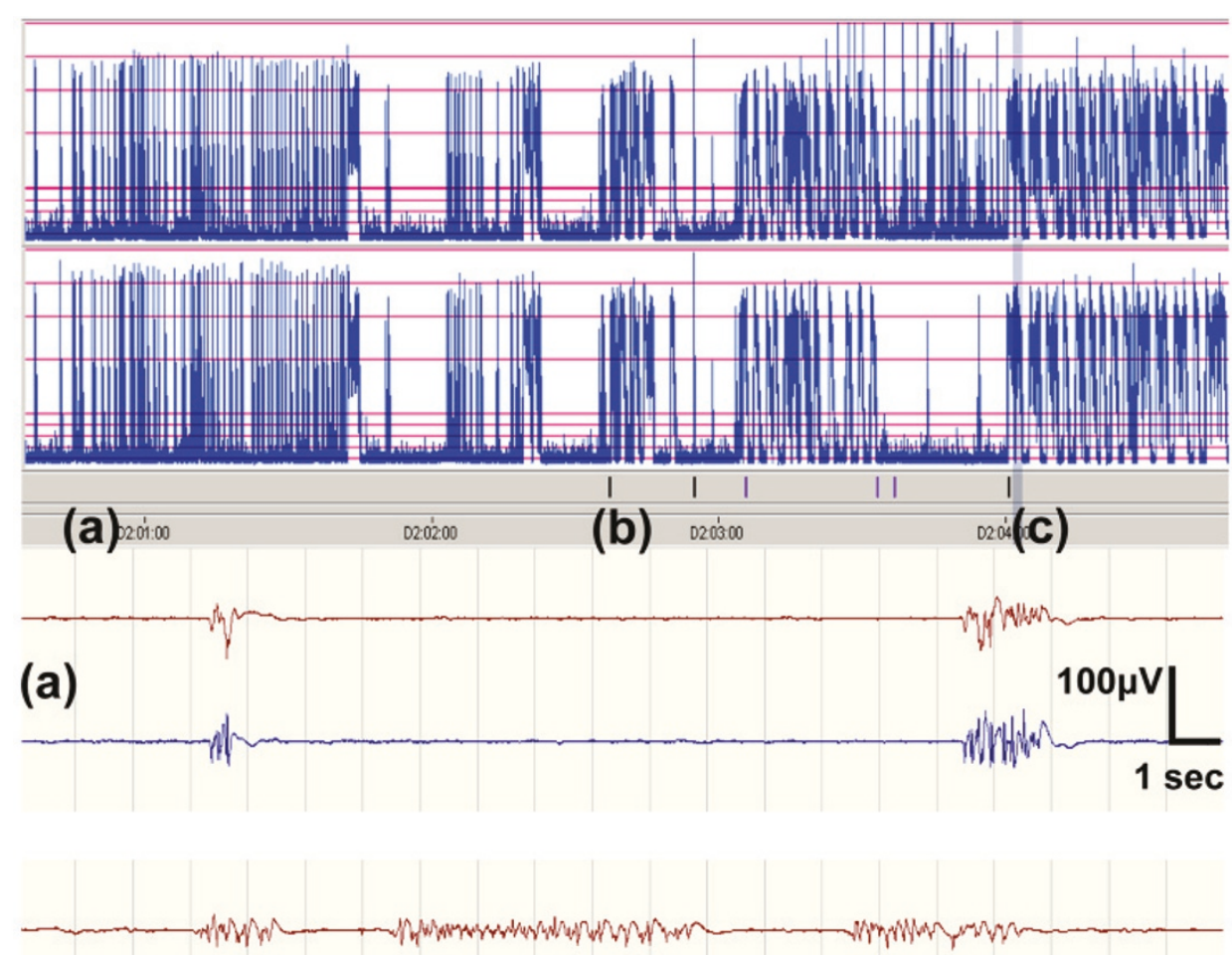

(b)
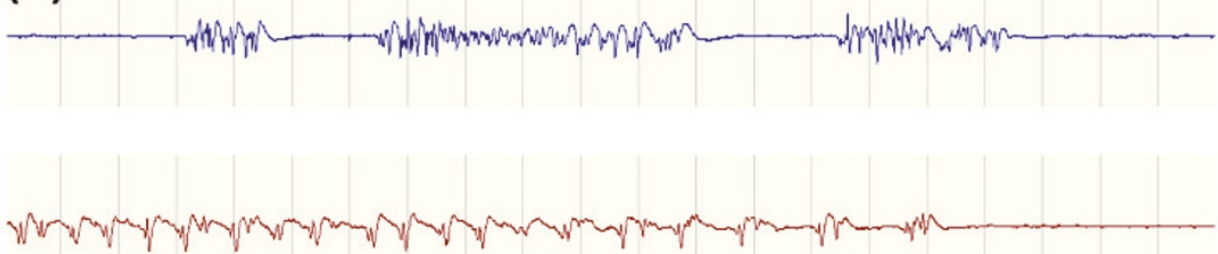

(c)

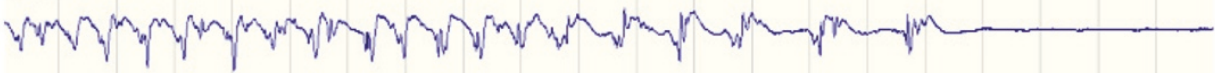

Figure 4. Electrographic status epilepticus (ESE) evolving from a burst suppression (BS) pattern. (a) BS pattern (12 hours after cardiac arrest). (b) BS pattern with short periods of repetitive epileptiform discharges (14 hours after cardiac arrest). (c) ESE with repeated electrographic seizures ( $>1 \mathrm{~Hz}$ ) for more than 30 minutes (16 hours after cardiac arrest).

meticulous study using intermittent EEG, Jørgensen and Holm [56] reported that cortical inactivity and a flat EEG curve are common immediately after cardiac arrest and that cortical activity eventually returns in most patients. Studies using a simplified cEEG montage have shown that initial cortical inactivity or a flat pattern $(<10 \mu \mathrm{V})$ is common during the early phase of hypothermia treatment after cardiac arrest but that it has no prognostic significance $[10,13]$. On the other hand, persistence of low-voltage or isoelectric patterns at 24 hours after the arrest was found to be a strong indicator of poor prognosis [5]. Evolution from a non-continuous to a continuous background pattern during hypothermia or at the time of normothermia is strongly associated with awakening and a good outcome $[5,10]$. A spontaneous and maintained burst suppression (BS) pattern after cardiac arrest indicates that the prognosis is poor in most [10], but not in all $[5,23,51]$, cases. This discrepancy between studies might be related to different definitions of BS since the development of a continuous background activity usually proceeds through a phase of intermittent cortical activity [57]. Our group has identified patients with two types of post-anoxic ESE, evolving from different background patterns; one develops early (typically during hypothermia) and from a BS background pattern (Figure 4). These patients had a uniformly poor outcome. The other type of ESE develops late (typically during or after rewarming) and from a continuous 


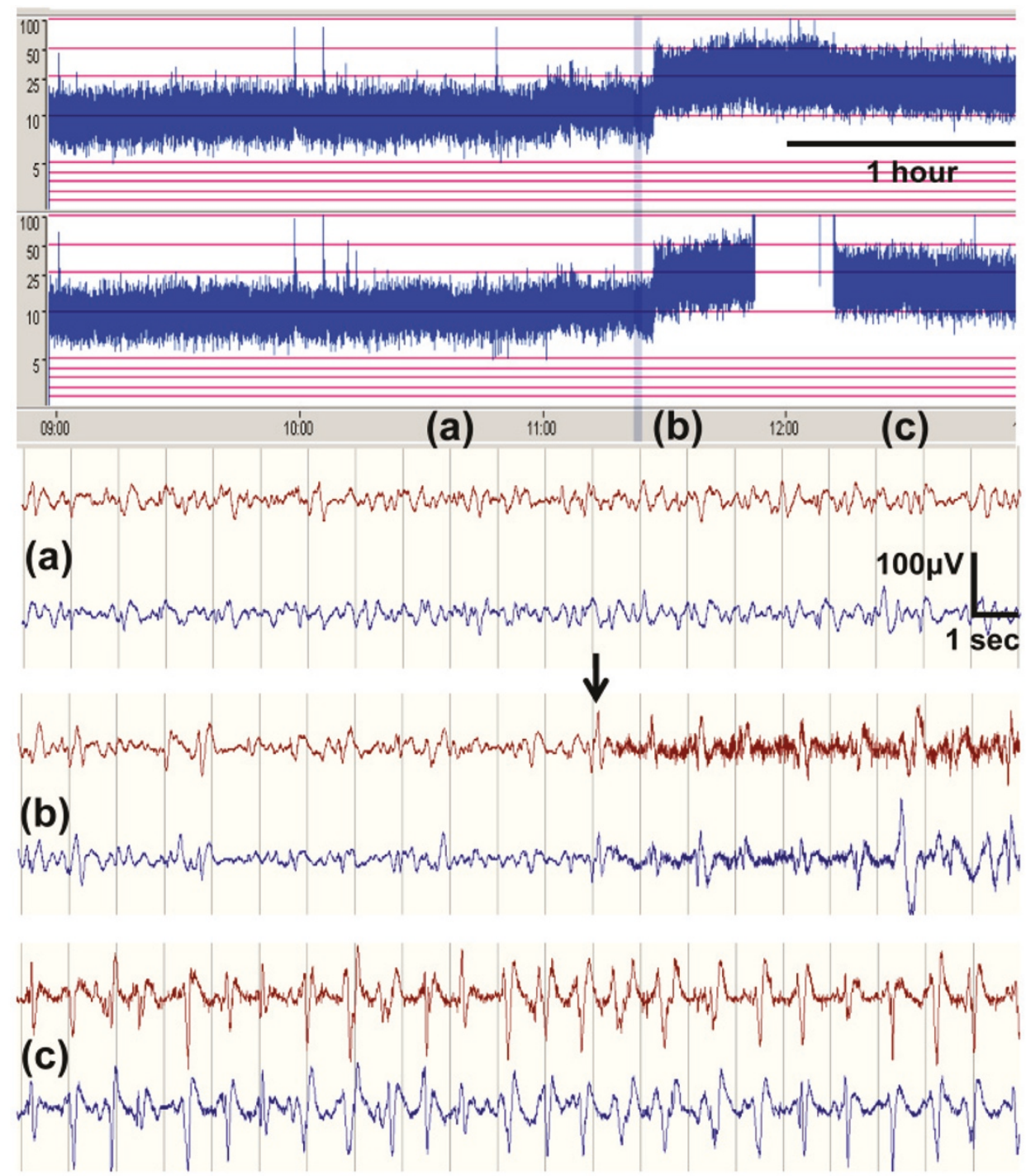

Figure 5. Electrographic status epilepticus (ESE) evolving from a continuous background pattern. (a) Continuous background (45 hours after cardiac arrest). (b) Onset (arrow) of repetitive epileptiform discharges ( $>1 \mathrm{~Hz},>30$ minutes), consistent with ESE (46 hours after cardiac arrest). (c) Ongoing ESE (47 hours after cardiac arrest).

background pattern (Figure 5), and in this group survivors were reported $[10,15]$.

\section{Patient categorization based on evolution of the electroencephalography}

Our experience in the ICU is that comatose patients after cardiac arrest can be categorized into one of three main groups. The three groups have different prognoses, and the use of cEEG is helpful in differentiating between them. In addition to using the simplified cEEG with a trend monitor, we use serial neurologic investigations and biomarker measurements and tailor the use of additional prognostic methods such as SSEP, routine EEG, and magnetic resonance imaging (MRI) on an individual basis.
The first group consists of comatose patients with a mild or limited brain injury characterized by return of a continuous and reactive EEG pattern during hypothermia. In this group, brain stem functions such as pupillary and corneal reflexes usually return early, and patients recover motor response to pain as sedation wears off. Levels of the brain damage biomarker neuron-specific enolase (NSE) are not elevated [15]. These patients are relatively easy to identify, and information to relatives should be cautiously positive.

The second group consists of patients with severe brain injury characterized by a flat or long-lasting BS EEG pattern, which often evolves into an ESE pattern during hypothermia (Figure 4), and still shows a malevolent and unreactive EEG pattern when sedation is stopped at 
normothermia. These patients often present with early myoclonus, and NSE levels are high. Corneal and pupillary reflexes may return, but the patients remain deeply comatose with an extensor or no response to pain. SSEP may be used to confirm the poor prognosis in most cases (no cortical responses) [15]. This group is also relatively easy to identify, and information to relatives should be pessimistic.

Third, there is a group with intermediate brain injury, which is the most difficult group to assess. These patients typically recover a cEEG pattern during hypothermia but with some epileptic activity that increases during rewarming and weaning from sedation, eventually evolving into ESE (Figure 5). The background EEG activity is usually reactive, SSEP responses are preserved, and NSE levels may be low or moderately increased. MRI typically does not show widespread ischemic damage [15]. Patients may develop myoclonus and even generalized tonic-clonic seizures but rarely during the first 24 hours. In this group of patients, we have experienced several survivors, and we would like to stress that observation time and active ICU care should be prolonged, possibly for 1 to 2 weeks or longer. Active treatment of ESE with sedatives and anti-epileptics mandates repeated routine EEGs or preferably cEEG guiding.

\section{Conclusions}

Simplified cEEG monitoring with a reduced montage and trend analysis is a convenient and promising method to monitor the evolution of EEG patterns and to detect and assess seizures in comatose patients after cardiac arrest. It provides dynamic information and is well suited to the ICU environment. Before simplified cEEG with trend analysis can reach general use, it should be validated against multichannel EEG recordings. We propose that not only a simplified cEEG montage with trend analysis but also a simplified system for interpretation of EEG rhythms with four defined major patterns be used. We hope that these actions will help disseminate the use of cEEG in ICUs in years to come.

\section{Abbreviations}

aEEG, amplitude-integrated electroencephalography; BS, burst suppression; CEEG, continuous electroencephalography; EEG, electroencephalography;

ESE, electrographic status epilepticus; ICU, intensive care unit; MRI, magnetic resonance imaging; NSE, neuron-specific enolase; GEEG, quantitative electroencephalography; SSEP, somatosensory evoked potential.

\section{Competing interests}

HF has received lecture fees from Natus Inc (San Carlos, CA, USA) (formerly CareFusion Inc). Natus Inc supports the trial'Prognostic value of EEG after cardiac arrest in TH and non-TH patients' with Nicolet ${ }^{\mathrm{TM}}$ monitors. All authors participated in this trial.

\section{Acknowledgments}

Funding was provided by the Thure Carlsson Foundation, the Hans-Gabriel and Alice Trolle-Wachtmeisters Foundation, Regional Research Support (Region Skåne) from Skåne University Hospital (Lund), and ALF (Academic Learning and Research grants) from Lund University (Sweden).

\section{Author details}

'Department of Intensive and Perioperative Care, Skåne University Hospital, Getingevägen, 22185 Lund, Sweden. ${ }^{2}$ Department of Clinical Sciences, Lund University, Getingevägen, 22185 Lund, Sweden. ${ }^{3}$ Department of Neurophysiology, Skåne University Hospital, Getingevägen, 22185 Lund, Sweden. ${ }^{4}$ Department of Anaesthesiology and Intensive Care, Helsingborg Hospital, Södra Vallgatan 5, 25437 Helsingborg, Sweden. ${ }^{5}$ Department of Neurology, Skåne University Hospital, Getingevägen, 22185 Lund, Sweden.

Published: 23 July 2013

\section{References}

1. Dragancea I, Rundgren $M$, Englund E, Friberg $H$, Cronberg T: The influence of induced hypothermia and delayed prognostication on the mode of death after cardiac arrest. Resuscitation 2013, 84:337-342.

2. Laver S, Farrow C, Turner D, Nolan J: Mode of death after admission to an intensive care unit following cardiac arrest. Intensive Care Med 2004, 30:2126-2128.

3. Deakin CD, Nolan JP, Soar J, Sunde K, Koster RW, Smith GB, Perkins GD: European Resuscitation Council Guidelines for Resuscitation 2010 Section 4. Adult advanced life support. Resuscitation 2010, 81:1305-1352.

4. Neumar RW, Nolan JP, Adrie C, Aibiki M, Berg RA, Bottiger BW, Callaway C, Clark RS, Geocadin RG, Jauch EC, Kern KB, Laurent I, Longstreth WT Jr., Merchant RM, Morley P, Morrison L, Nadkarni V, Peberdy MA, Rivers EP, Rodriguez-Nunez A, Sellke FW, Spaulding C, Sunde K, Vanden Hoek T: Postcardiac arrest syndrome: epidemiology, pathophysiology, treatment, and prognostication. A consensus statement from the International Liaison Committee on Resuscitation (American Heart Association, Australian and New Zealand Council on Resuscitation, European Resuscitation Council, Heart and Stroke Foundation of Canada, InterAmerican Heart Foundation, Resuscitation Council of Asia, and the Resuscitation Council of Southern Africa); the American Heart Association Emergency Cardiovascular Care Committee; the Council on Cardiovascular Surgery and Anesthesia; the Council on Cardiopulmonary, Perioperative, and Critical Care; the Council on Clinical Cardiology; and the Stroke Council. Circulation 2008, 118:2452-2483.

5. Cloostermans MC, van Meulen FB, Eertman CJ, Hom HW, van Putten MJ: Continuous electroencephalography monitoring for early prediction of neurological outcome in postanoxic patients after cardiac arrest: a prospective cohort study. Crit Care Med 2012, 40:2867-2875.

6. Legriel S, Hilly-Ginoux J, Resche-Rigon M, Merceron S, Pinoteau J, HenryLagarrigue M, Bruneel F, Nguyen A, Guezennec P, Troche G, Richard O, Pico F, Bedos JP: Prognostic value of electrographic postanoxic status epilepticus in comatose cardiac-arrest survivors in the therapeutic hypothermia era. Resuscitation 2013, 84:343-350.

7. Nielsen N, Hovdenes J, Nilsson F, Rubertsson S, Stammet P, Sunde K, Valsson F, Wanscher $\mathrm{M}$, Friberg H: Outcome, timing and adverse events in therapeutic hypothermia after out-of-hospital cardiac arrest. Acta Anaesthesiol Scand 2009, 53:926-934.

8. Rittenberger JC, Popescu A, Brenner RP, Guyette FX, Callaway CW: Frequency and timing of nonconvulsive status epilepticus in comatose post-cardiac arrest subjects treated with hypothermia. Neurocrit Care 2012, 16:114-122.

9. Rossetti AO, Logroscino G, Liaudet L, Ruffieux C, Ribordy V, Schaller MD, Despland PA, Oddo M: Status epilepticus: an independent outcome predictor after cerebral anoxia. Neurology 2007, 69:255-260.

10. Rundgren M, Westhall E, Cronberg T, Rosen I, Friberg H: Continuous amplitude-integrated electroencephalogram predicts outcome in hypothermia-treated cardiac arrest patients. Crit Care Med 2010, 38:1838-1844.

11. Friedman D, Claassen J, Hirsch LJ: Continuous electroencephalogram monitoring in the intensive care unit. Anesth Analg 2009, 109:506-523.

12. Oh SH, Park KN, Kim YM, Kim HJ, Youn CS, Kim SH, Choi SP, Kim SC, Shon YM: The prognostic value of continuous amplitude-integrated electroencephalogram applied immediately after return of spontaneous circulation in therapeutic hypothermia-treated cardiac arrest patients. Resuscitation 2013, 84:200-205.

13. Rundgren M, Rosen I, Friberg H: Amplitude-integrated EEG (aEEG) predicts outcome after cardiac arrest and induced hypothermia. Intensive Care Med 2006, 32:836-842.

14. Schefold JC, Storm C, Kruger A, Ploner CJ, Hasper D: The Glasgow Coma Score is a predictor of good outcome in cardiac arrest patients treated 
with therapeutic hypothermia. Resuscitation 2009, 80:658-661.

15. Cronberg T, Rundgren M, Westhall E, Englund E, Siemund R, Rosen I, Widner $\mathrm{H}$, Friberg $\mathrm{H}$ : Neuron-specific enolase correlates with other prognostic markers after cardiac arrest. Neurology 2011, 77:623-630.

16. Hovland A, Nielsen EW, Kluver J, Salvesen R: EEG should be performed during induced hypothermia. Resuscitation 2006, 68:143-146.

17. Rossetti AO, Oddo M, Liaudet L, Kaplan PW: Predictors of awakening from postanoxic status epilepticus after therapeutic hypothermia. Neurology 2009, 72:744-749.

18. Sunde K, Dunlop O, Rostrup M, Sandberg M, Sjoholm H, Jacobsen D: Determination of prognosis after cardiac arrest may be more difficult after introduction of therapeutic hypothermia. Resuscitation 2006, 69:29-32.

19. Friberg H, Rundgren M, Westhall E, Nielsen N, Cronberg T: Continuous evaluation of neurological prognosis after cardiac arrest. Acta Anaesthesiol Scand 2013, 57:6-15.

20. Oddo M, Rossetti AO: Predicting neurological outcome after cardiac arrest. Curr Opin Crit Care 2011, 17:254-259

21. Samaniego EA, Persoon S, Wijman CA: Prognosis after cardiac arrest and hypothermia: a new paradigm. Curr Neurol Neurosci Rep 2011, 11:111-119.

22. Jørgensen EO, Holm S: Prediction of neurological outcome after cardiopulmonary resuscitation. Resuscitation 1999, 41:145-152.

23. Rossetti AO, Carrera E, Oddo M: Early EEG correlates of neuronal injury after brain anoxia. Neurology 2012, 78:796-802.

24. Bouwes A, Binnekade JM, Kuiper MA, Bosch FH, Zandstra DF, Toornvliet AC, Biemond HS, Kors BM, Koelman JH, Verbeek MM, Weinstein HC, Hijdra A, Horn $\mathrm{J}$ : Prognosis of coma after therapeutic hypothermia: a prospective cohort study. Ann Neurol 2012, 71:206-212.

25. Zandbergen EG, Hijdra A, Koelman JH, Hart AA, Vos PE, Verbeek MM, de Haan RJ: Prediction of poor outcome within the first 3 days of postanoxic coma. Neurology 2006, 66:62-68.

26. Scolletta S, Donadello K, Santonocito C, Franchi F, Taccone FS: Biomarkers as predictors of outcome after cardiac arrest. Expert Rev Clin Pharmacol 2012, 5:687-699.

27. Wijman CA, Mlynash M, Caulfield AF, Hsia AW, Eyngorn I, Bammer R, Fischbein $\mathrm{N}$, Albers GW, Moseley M: Prognostic value of brain diffusion-weighted imaging after cardiac arrest. Ann Neurol 2009, 65:394-402.

28. Stecker MM, Cheung AT, Pochettino A, Kent GP, Patterson T, Weiss SJ, Bavaria JE: Deep hypothermic circulatory arrest: I. Effects of cooling on electroencephalogram and evoked potentials. Ann Thorac Surg 2001, 71:14-21

29. Rossetti AO, Urbano LA, Delodder F, Kaplan PW, Oddo M: Prognostic value of continuous EEG monitoring during therapeutic hypothermia after cardiac arrest. Crit Care 2010, 14:R173.

30. Bouwes A, van Poppelen D, Koelman JH, Kuiper MA, Zandstra DF, Weinstein HC, Tromp SC, Zandbergen EG, Tijssen MA, Horn J: Acute posthypoxic myoclonus after cardiopulmonary resuscitation. BMC Neurol 2012, 12:63.

31. Hellstrom-Westas L, Rosen I, Svenningsen NW: Predictive value of early continuous amplitude integrated EEG recordings on outcome after severe birth asphyxia in full term infants. Arch Dis Child Fetal Neonatal Ed 1995, 72:F34-38.

32. Hellström-Westas $L$, de Vries $L$, Rosén I: An Atlas of Amplitude Integrated EEGs in the Newborn. 2nd edition. London, UK: Informa Healthcare; 2008.

33. Abend NS, Topjian A, Ichord R, Herman ST, Helfaer M, Donnelly M, Nadkarni V, Dlugos DJ, Clancy RR: Electroencephalographic monitoring during hypothermia after pediatric cardiac arrest. Neurology 2009, 72:1931-1940.

34. Sutter R, Fuhr P, Grize L, Marsch S, Ruegg S: Continuous video-EEG monitoring increases detection rate of nonconvulsive status epilepticus in the ICU. Epilepsia 2011, 52:453-457.

35. Vespa PM, McArthur DL, Xu Y, Eliseo M, Etchepare M, Dinov I, Alger J, Glenn TP, Hovda D: Nonconvulsive seizures after traumatic brain injury are associated with hippocampal atrophy. Neurology 2010, 75:792-798.

36. Lindgren C, Nordh E, Naredi S, Olivecrona M: Frequency of non-convulsive seizures and non-convulsive status epilepticus in subarachnoid hemorrhage patients in need of controlled ventilation and sedation. Neurocrit Care 2012, 17:367-373.

37. El-Dib M, Chang T, Tsuchida TN, Clancy RR: Amplitude-integrated electroencephalography in neonates. Pediatr Neurol 2009, 41:315-326.

38. Young GB, Sharpe MD, Savard M, AI Thenayan E, Norton L, Davies-Schinkel C: Seizure detection with a commercially available bedside EEG monitor and the subhairline montage. Neurocrit Care 2009, 11:411-416.

39. Cloostermans MC, de Vos CC, van Putten MJ: A novel approach for computer assisted EEG monitoring in the adult ICU. Clin Neurophysiol 2011, 122:2100-2109.

40. Scheuer ML, Wilson SB: Data analysis for continuous EEG monitoring in the ICU: seeing the forest and the trees. J Clin Neurophysiol 2004, 21:353-378.

41. Shah AK, Agarwal R, Carhuapoma JR, Loeb JA: Compressed EEG pattern analysis for critically ill neurological-neurosurgical patients. Neurocrit Care 2006, 5:124-133.

42. Hirsch L, Brenner R (eds.): Atlas of EEG in Critical Care. 1st edition. Hoboken, NJ, USA: Wiley; 2010

43. Rosen I: The physiological basis for continuous electroencephalogram monitoring in the neonate. Clin Perinatol 2006, 33:593-611, v.

44. Whitelaw A, White RD: Training neonatal staff in recording and reporting continuous electroencephalography. Clin Perinatol 2006, 33:667-677, vii.

45. Osredkar D, Toet MC, van Rooij LG, van Huffelen AC, Groenendaal F, de Vries LS: Sleep-wake cycling on amplitude-integrated electroencephalography in term newborns with hypoxic-ischemic encephalopathy. Pediatrics 2005 , 115:327-332.

46. Thoresen M, Hellstrom-Westas L, Liu X, de Vries LS: Effect of hypothermia on amplitude-integrated electroencephalogram in infants with asphyxia. Pediatrics 2010, 126:e131-139.

47. Benbadis SR, Chen S, Melo M: What's shaking in the ICU? The differential diagnosis of seizures in the intensive care setting. Epilepsia 2010, 51:2338-2340.

48. Bauer G, Trinka E: Nonconvulsive status epilepticus and coma. Epilepsia 2010, 51:177-190.

49. Thomke F, Marx JJ, Sauer O, Hundsberger T, Hagele S, Wiechelt J, Weilemann $S L$ : Observations on comatose survivors of cardiopulmonary resuscitation with generalized myoclonus. BMC Neurol 2005, 5:14.

50. Wijdicks EF, Young GB: Myoclonus status in comatose patients after cardiac arrest. Lancet 1994, 343:1642-1643.

51. Lucas JM, Cocchi MN, Salciccioli J, Stanbridge JA, Geocadin RG, Herman ST, Donnino MW: Neurologic recovery after therapeutic hypothermia in patients with post-cardiac arrest myoclonus. Resuscitation 2012 83:265-269.

52. Morris HR, Howard RS, Brown P: Early myoclonic status and outcome after cardiorespiratory arrest. J Neurol Neurosurg Psychiatry 1998, 64:267-268.

53. Werhahn KJ, Brown P, Thompson PD, Marsden CD: The clinical features and prognosis of chronic posthypoxic myoclonus. Mov Disord 1997, 12:216-220

54. Ko SB, Ortega-Gutierrez S, Choi HA, Claassen J, Presciutti M, Schmidt JM, Badjatia N, Lee K, Mayer SA: Status epilepticus-induced hyperemia and brain tissue hypoxia after cardiac arrest. Arch Neurol 2011, 68:1323-1326.

55. Rabinstein AA, Wijdicks EF: The value of EEG monitoring after cardiac arrest treated with hypothermia. Neurology 2012, 78:774-775

56. Jørgensen $\mathrm{EO}, \mathrm{Holm} \mathrm{S}$ : The natural course of neurological recovery following cardiopulmonary resuscitation. Resuscitation 1998, 36:111-122

57. Jørgensen EO, Malchow-Moller A: Natural history of global and critical brain ischaemia. Part II: EEG and neurological signs in patients remaining unconscious after cardiopulmonary resuscitation. Resuscitation 1981, 9:155-174.

doi:10.1186/cc12699

Cite this article as: Friberg $\mathrm{H}$, et al:: Clinical review: Continuous and simplified electroencephalography to monitor brain recovery after cardiac arrest. Critical Care 2013, 17:233. 


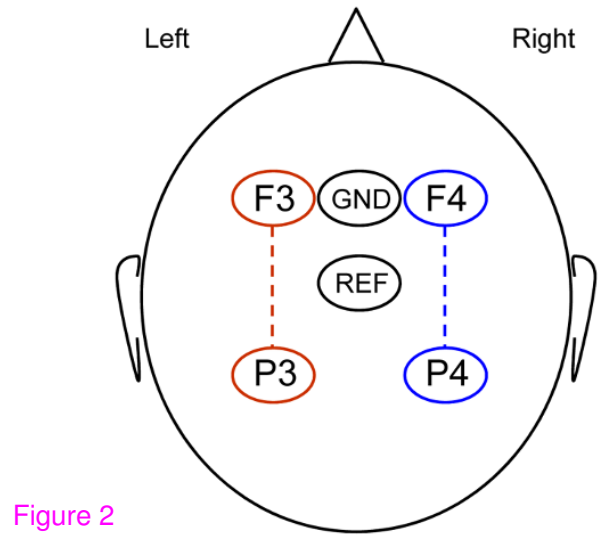


(a)

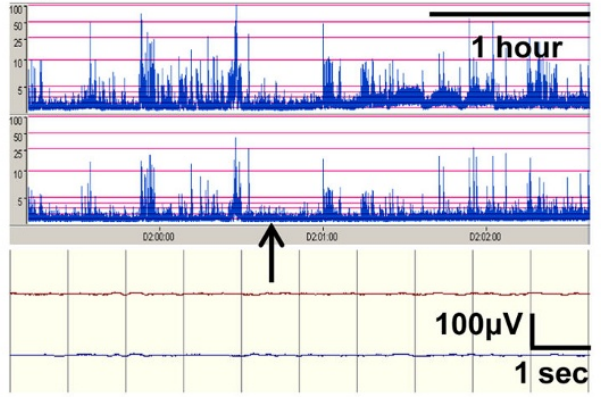

(c)

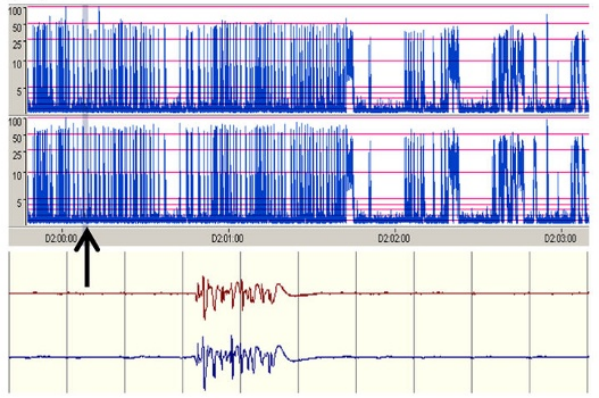

(b)

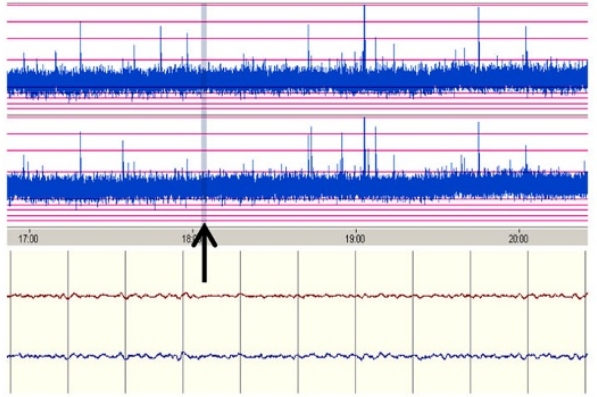

(d)
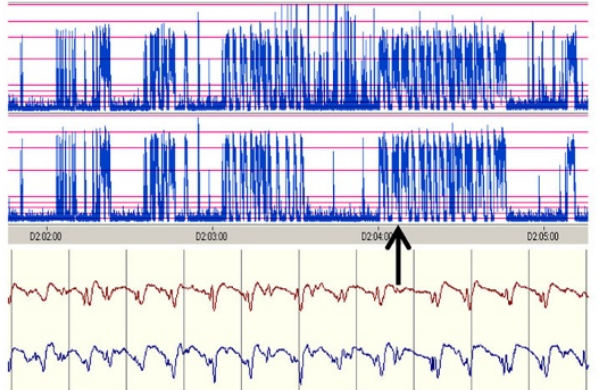

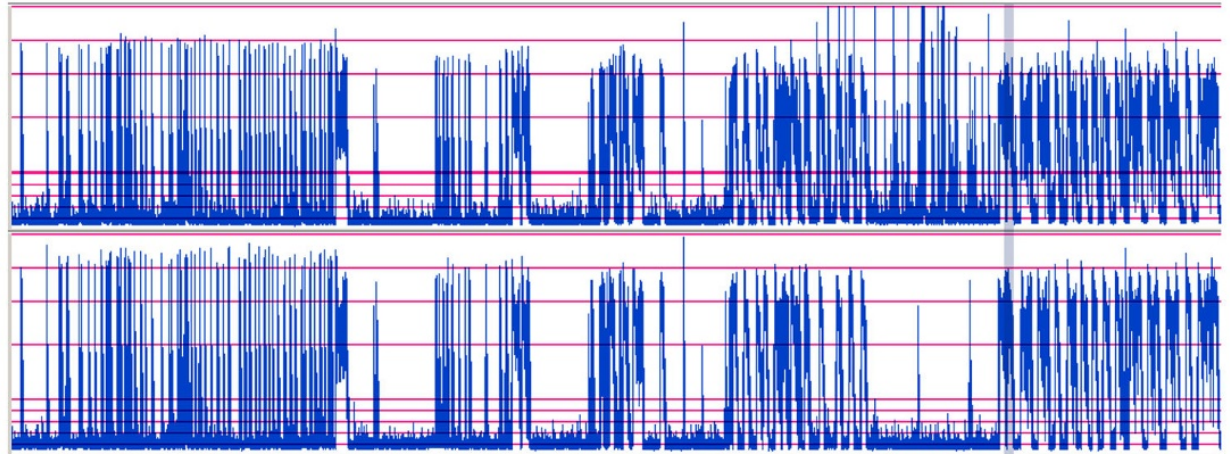
(a) $201: 00$
$\begin{array}{ll}\text { (b) } & 1 \\ \text { (b2:03:00 }\end{array}$
$\begin{array}{ll}\mid 1 & 1 \\ 0204(\mathrm{C})\end{array}$
D2:02:00

(a)

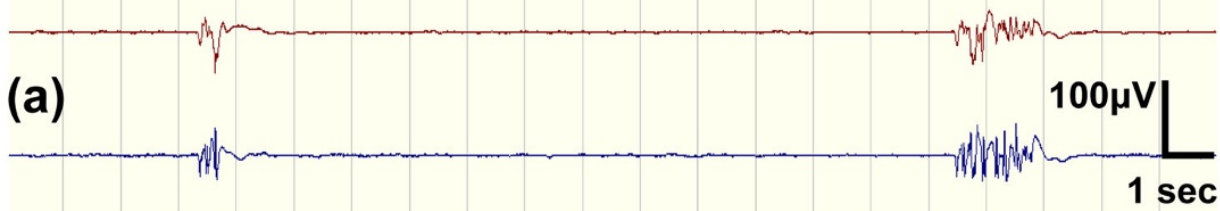

whon w

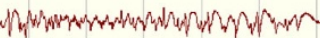

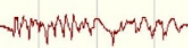

(b)

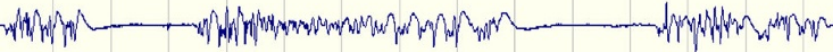

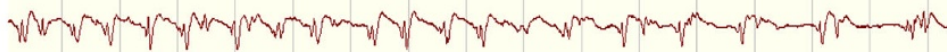

\section{(c)}


